\title{
Fungitoxic effects of some plant extracts on seedborne fungi pathogens of Bambara groundnut in Awka South of Anambra State, Nigeria
}

\section{Christian Chukwunenye Iwuagwu ${ }^{1 *}$, Raphael Chinoyelum Kpadobi ${ }^{1}$, Andrew Chukwuma Nwogbaga ${ }^{2}$, Muhammadu Tajudeen Salaudeen ${ }^{3}$, Donald Ezechukwu Iheaturu ${ }^{1}$ and Francis Chukwuma Onejeme ${ }^{1}$}

\author{
${ }^{1}$ Department of Crop Science and Horticulture, Nnamdi Azikiwe University Awka Anambra State, Nigeria. \\ ${ }^{2}$ Department of Crop Production and Landscape Management, Ebonyi State University, Abakaliki, Ebonyi State, Nigeria. \\ ${ }^{3}$ Department of Crop Production, Federal University of Technology, Minna, Niger State, Nigeria.
}

Accepted 12 April, 2019

\begin{abstract}
The research was carried out to test the effect of turmeric and garlic extracts on seed borne fungi pathogens of Bambara groundnut (Vigna subterranean) in Awka South of Anambra State Nigeria. Seed health test of Bambara groundnut seeds sampled from Awka main market was achieved by blotter paper method. The potentials of the isolated organisms to cause diseases was tested in a pathogenicity test using Koch's procedures. Antifungal effect of methanol and ethyl acetate extracts of tumeric (Curcuma longa) and garlic (Allium sativum) was investigated in an in-vitro experiment against the isolated seed borne pathogens of Bambara groundnut and synthetic fungicide (Mancozeb) as a standard control. The result of pathogenicity test revealed that Aspergillus niger, isolated from Bambara groundnut seeds was pathogenic. The result also showed that all the two plant extracts and synthetic fungicide were effective in inhibiting radial growth of Aspergillus niger which was the only fungi pathogen isolated. Curcuma longa performed closely rated to Mancozeb in the in-vitro experiment, having (75.00, 75.00 and $75.00 \%)$ and $(72.56,60.82$ and $50.94 \%)$ respectively in the three days in culture. The higher the concentration the higher the inhibition values as 30 $\mathrm{g} / \mathrm{ml}$ consistently gave the highest inhibition values. Also Soxhlet extraction method did better than cold maceration in days 2, 3 in culture. The research have shown that fungitoxic compounds from Curcuma longa could be explored as an eco-friendly alternative to synthetic fungicide (Mancozeb) in the control of Aspergillus niger on Bambara groundnut seeds.
\end{abstract}

Keywords: Bambara groundnut, seedborne pathogens, plant extracts, fungitoxic effect, Nigeria.

${ }^{*}$ Corresponding author. E-mail: chrisiwuag@yahoo.com. Tel: +2348061156141.

\section{INTRODUCTION}

Bambara groundnut (Vigna subterranea (L) Verdc.) is an African species and a member of the Fabaceae family, which is indigenous to sub-tropical Africa where it is widely cultivated. It is also known by its common names like Bambara groundnut, Bambara-bean, Congo goober, earth pea, ground bean, or hog peanut.

The plant originated in West Africa. The center of origin is most likely north-eastern Nigeria and northern Cameroon, in Central Africa. Although occasionally grown in Asia and elsewhere, its cultivation is rare outside the African continent. Asian countries like India, Malaysia, Philippines and Thailand also cultivate it. According to Yao et al. (2005), for instance, Bambara groundnut plays a key role in the traditional food and culture of peoples in the western and northern parts of Cote d'Ivoire.

Bambara groundnut is now widely distributed in the semi-arid zone of sub-Saharan Africa (SSA) and most 
authors seem to support the view that it is the third most important food legume after cowpea (Vigna unguiculata) and groundnut (Arachis hypogeal) (Mkandawire, 2007). It is cultivated for its subterranean pods, which is extremely hardy and produces reasonable yields even under conditions of drought and low soil fertility. The pods are approximately $1.5 \mathrm{~cm}$ long, and may be wrinkled and slightly oval or round, containing one to two seeds. The plant is extracted from the soil, exposing the subterranean nuts. The nuts may be eaten fresh by boiling or roasted as snacks but the majority of the nuts are consumed after they are dried.

Bambara groundnut is important for smallholders and their households because the beans are an important source of food, being nutritious and high in protein (Azam-Ali et.al., 2001). Although, as common with other legumes, bambara groundnut is deficient in Sulphur containing amino acids (Azam-Ali et al., 2001). Some genotypes contain higher amounts of methionine and lysine than is found in other legumes (NRC, 2006).

Bambara groundnut is not easily attacked by diseases and pests in any of its production stages. However, in damp conditions, it may be susceptible to various fungal diseases (Baudoin and Mergeai, 2001). It has a very low insect-pest and disease susceptibility (Tweneboah, 2000).

However, there are various post-harvest losses of Bambara groundnut which serves as a major constraint to increased and sustainable production of Bambara groundnut, particularly grains are most susceptible to insect infestation and destruction. The destruction may start from the field, but serious insect damage occurs during storage (Amuti and Larbi, 1981; Warui, 1984; FAO, 1985; Golob et al., 1996). These diseases are being controlled by mostly synthetic fungicides, which are in the recent time gradually becoming unpopular as prophylactic means of combating them. The reason stems from its persistency in food materials and environment as well as high resistance by mycopathogens (Golob et al., 1996), which is now making way for more ecofriendly phytochemicals such as those used in this study (Golob et al., 1996).

The study of addition of turmeric powder in plant tissue culture showed that turmeric at 0.8 and $1.0 \mathrm{~g} / \mathrm{L}$ had appreciable inhibitory activity against fungal contaminations (Upendra et al., 2011). The methanol extract of turmeric demonstrated antifungal activity against Cryptococcus neoformans and Candida albicans with MIC values of 128 and $256 \mu \mathrm{g} / \mathrm{ml}$, respectively (Ungphaiboon et al., 2005). Curcumin and turmeric oil exert antifungal effect against two phytopathogenic fungi, namely, Fusarium solani and Helminthosporium oryzae (Chowdhury et al., 2008). Turmeric oil exhibited the most effective antifungal activity against $F$. solani and $H$. oryzae with $\mathrm{IC}_{50}$ of 19.73 and $12.7 \mu \mathrm{g} / \mathrm{ml}$, respectively (Chowdhury et al., 2008). Also garlic has anti-feedant, bactericidal, fungicidal, insecticidal, nematicidal and repellent properties (Chowdhury et al., 2008). Garlic is reportedly effective against a wide range of diseasecausing pathogens and insects at different stages in their life cycle. Garlic is non-selective; it has a broad-spectrum effect and can kill beneficial insects as well. Therefore, it should be used with caution (Ellis and Bradley, 1992).

\section{MATERIALS AND METHODS}

\section{Germination test}

Germination test was carried out to ensure the viability of the seeds obtained. The pre- germination test includes - sowing directly in the soil. That was done by sowing the seeds into white sand to test the viability of the seeds. Also blotter paper method was used to test the seed viability.

\section{Blotter paper method}

Here, the seeds were washed in a mixture of ethanol and distilled water (surface sterilization), after which they were sprayed to dry in between two layers of blotter paper. After that three layers of blotter paper were placed in each of the Petri dish of $9 \mathrm{~cm}$ diameter and incubated at $25 \pm 2^{\circ} \mathrm{C}$. Six seeds were placed in each Petri dish and ten replicates were made after which a masking tape was used to seal it to prevent any form of contamination. The percent germination of Bambara groundnut seed were calculated after five days (De Tempe, 1963).

\section{Preparation of PDA}

Twenty (20) grams of PDA was weighed with the electronic weighing balance and was mixed in $500 \mathrm{ml}$ of distilled water in a conical flask. The mixture was stirred vigorously until it becomes homogenous. It was then corked, using cotton wool wrapped with foil before being placed into the autoclave.

\section{Autoclaving procedure}

The autoclave used was the portable steam autoclave. The conical flask containing PDA was placed into the autoclave and was properly sealed. The autoclave was set at a temperature of $120^{\circ} \mathrm{C}$ and pressure of $15 \pm 1$ Psi for 20 min after which it was ready for use.

\section{Isolation of fungal pathogen}

The working bench was surface sterilized with methylated spirit and cotton wool so as to prevent contamination. A sterile inoculating loop was used to place the infection from the seeds into sterile petri dishes containing $10 \mathrm{ml}$ of PDA with two drops of lactic acid. The lactic acid was added to inhibit the growth of bacteria. The Petri dishes were properly sealed and labeled. The plates with 5 replicates were incubated at temperature $\left(28 \pm 2^{\circ} \mathrm{C}\right)$ and left for seven days and closely observed daily for growth of fungi.

\section{Sub-culturing of fungal pathogen}

The initial culture was sub-cultured three times to obtain a pure culture. The method used in sub culturing was the streaking method using the inoculating loop. Here, a sterile inoculating loop was used to slightly touch the culture, then giving three lines (streaks) into the 
fresh plate of a prepared PDA after which, it was sealed for preventing contamination. The sub culture was left for three days and observed daily for growth of fungi.

The resulting pure cultures were used for subsequent identification and characterization of the fungi isolates with the aid of a compound microscope and identification guides (Sulton, 1980).

\section{Identification of isolated fungal pathogen}

A compound microscope with model (Olympus-XN 50) was used to view the organisms. Sterilized slides were used. A drop of distilled water was placed on the slide and a small portion of the culture from the seven-day culture was collected from the growth using a sterile needle, it was then covered with the slide cover and placed under the microscope for viewing.

\section{Preparation of plant materials for extraction}

The plant materials were thoroughly washed in tap water followed by sterile water. The plant extracts were cut into smaller parts and was then taken to the laboratory and oven dried at a temperature of $105^{\circ} \mathrm{C}$ for 30 min using laboratory oven. Hundred grams of the plant materials was weighed out with the aid of electronic weighing balance, after grinding them using Master chef electric blender into powder for use in the study.

\section{Methanol extraction}

Using cold solvent extraction method (Azwanida, 2015) $50 \mathrm{~g}$ of turmeric and garlic was soaked in $500 \mathrm{ml}$ of methanol respectively, in a white plastic container for 2 days with vigorous shaking at intervals during this period. The extracts were then filtered with white cheese cloth first and then filtered again with the use of Buckner funnel. Then methanol was evaporated to dryness by placing it in water bath at a temperature of $60^{\circ} \mathrm{C}$.

\section{Hot continuous extraction (soxhlet) with ethyl acetate}

Fifty grams of each plant materials (turmeric and garlic) were weighed out respectively and placed into the thimble. Paper thimble was used in the Soxhlet apparatus, using ethyl acetate as the extracting solvent. After extraction the ethyl acetate evaporated to dryness by placing the filtrates in a rotary evaporator.

The plant extracts were dissolved in $10 \mathrm{ml}$ of Dimethyl Sulfoxide (DMSO). 10, 20 and $30 \mathrm{~g}$ portion of each plant extract were mixed with $100 \mathrm{ml}$ of distilled water into a measuring cylinder to produce percentage concentrations of the extracts.

\section{Pathogenicity test}

This test was carried out using the test organisms (Aspergillus niger) from the two varieties of Bambara groundnut seeds. Three seeds were planted on polybags perforated at the bottom each containing sterilized soil. This was replicated ten times. The soil used was heated at temperature of $100^{\circ} \mathrm{C}$ for three hours to prevent any form of contamination, after which $2 \mathrm{~kg}$ was weighed into each polybag.

The pathogenicity test was done in the screen house of the Department of Crop Science and Horticulture, Faculty of Agriculture, Nnamdi Azikiwe University, Awka. An agar block measuring $4 \mathrm{~cm}$ by $4 \mathrm{~cm}$ from growing pure culture of the test isolate was poured into a solution made from corn starch. It was made with hot water after which it was allowed to cool, and poured into a hand operated pump. The mixture was then sprayed on the twenty-four Bambara groundnut seedlings in the screen house. The corn starch served as a sticker for the organism to remain on the leaves. After one month, symptoms were observed which are round or irregular lesions on the leaf axil, the lesions enlarged rapidly having concentric colour patterns, which covers the entire leaf and damage it within a few weeks leading to eventual death of the plant.

\section{Effect of plant extracts on fungal growth}

Effect of plant extract on mycelia growth of the isolated fungi was studied using the poisoned food technique (Sangoyomi, 2004). One milliliter of each plant extract concentrations $(10,20$ and $30 \mathrm{~g} / \mathrm{ml})$ was poured per petri dishes and $15 \mathrm{ml}$ of the media (molten PDA) was added to each of the petri dishes containing extract and carefully spread evenly over the plate, this gave rise to PDA-extract mixture. The plates were gently rotated to ensure even dispersion of the extracts. The agar extract mixture was allowed to solidify and then inoculated at the center with a $4 \mathrm{~mm}$ diameter disc obtained from the colony edge of a 7-day old pure culture of the test fungi. Each treatment consists of three replicates. The control consist of blank agar plate (no extract) inoculated with the test fungi as described above. Petri dishes dispensed with molten PDA and $1 \mathrm{ml}$ of Mancozeb plus at $10 \mathrm{~g}, 20 \mathrm{~g}, 30 \mathrm{~g}$ concentrations, inoculated with the test fungus served as the commercial fungicide. All the plates were incubated at $28 \pm 2^{\circ} \mathrm{C}$ for 3 days and examined daily for growth inhibition. Colony diameter was taken as the mean growth along on the reverse side of the plates. The effectiveness of the extract was recorded in terms of percentage inhibition, which was calculated according to the method described by Whipps (1987).

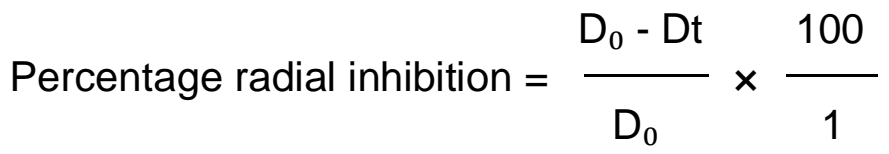

Where $D_{0}$ is the distance of radial spread in control plate while Dt is the distance of radial spread in extract incorporated agar plates.

\section{Experimental design}

The experimental design used was split-plot design laid in a Complete Randomized Design (CRD). The data collected were subjected to Analysis of Variance (ANOVA) and means were separated using least significant difference (LSD) at 0.05 probability level. The Genstat 7.2 version was used for all the statistical analysis. The major factor used in this work is the plant extract, subfactor is the different concentration levels and the sub-sub factor is the method of extraction and solvent used in extraction.

\section{RESULTS}

\section{Germination percentage of Cream white (Variety A) and Black speckled (Variety B)}

Figure 1 shows the germination percentage of cream white bean (Var A) and black speckled (Var B) for five days; the highest germination percentage was seen at day five, Variety A had $36.7 \%$ and Variety B had $50 \%$. There was no germination observed on day 1 , day 2 and day 3. Variety A had $18 \%$ and Variety B had $30 \%$, 


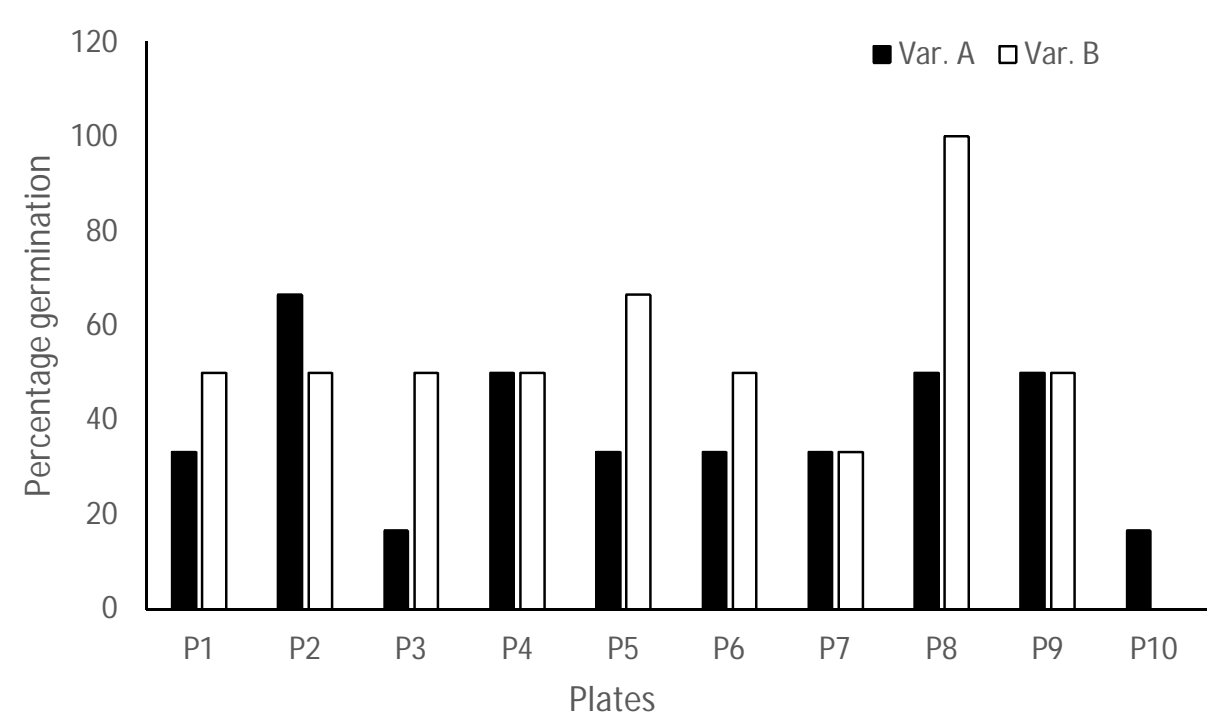

Figure 1. Germination percentage of Cream white bean and Black speckled bean.

respectively on day 4.

\section{Seed borne fungal pathogen isolated from the infected Bambara groundnut seeds}

The fungal organism identified in the course of isolation of fungi pathogen carried out on Bambara groundnut seeds was Aspergillus niger (Plate 1).

Identification of the fungi pathogen was based on the morphology of the culture and the fruiting bodies. An illustrated manual on identification of fungi by Barnett and Hunter (1999) and Alexopolus et al. (2002) were used for confirmation of the identification. (Plate 2)

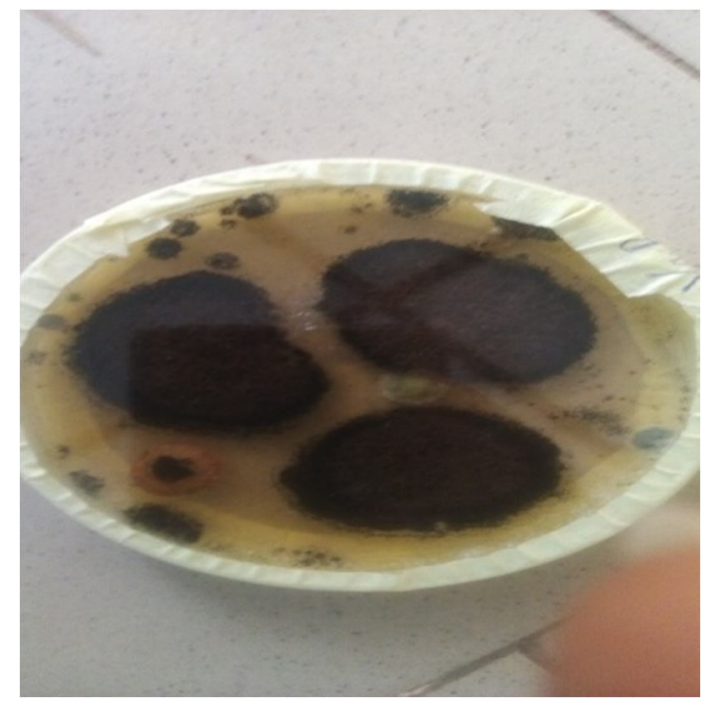

Plate 1. Pure culture of Aspergillus niger isolated from the infected Bambara groundnut seeds.

\section{Pathogenicity of the fungi isolate}

The result of the comparison of symptoms observed in the field and those that manifested after artificial inoculation in the improvised screen house showed a great similarity in terms of lesions seen on the vegetative parts of the Bambara groundnut. The result also showed that the re-isolated fungal organism confirmed that the fungus inoculated was actually the cause of the disease symptoms observed in the field according to Kock's postulate. This is in agreement with several report such as by Markson et al. (2014) and Akhtar et al. (2009). All these researchers have used artificial inoculation of fungi spores isolated from infected tissue of various plant species into healthy ones and later re-isolated the same fungi inoculated with the confirmatory characteristics as were seen on those isolated from the infected ones before the test. (Plates 3 to 5 )

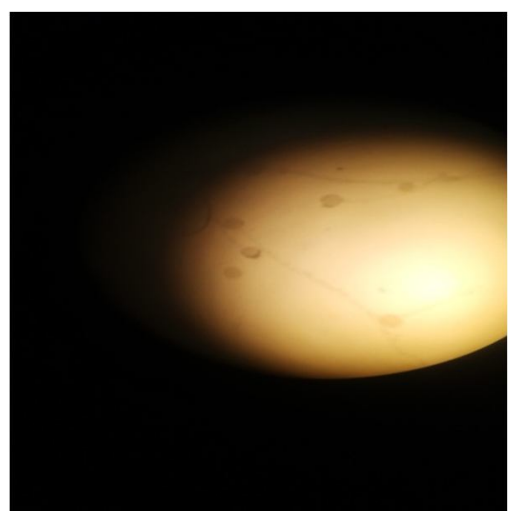

Plate 2. Micrograph of Aspergillus niger $(\times 100)$ isolated from infected Bambara groundnut, respectively. 


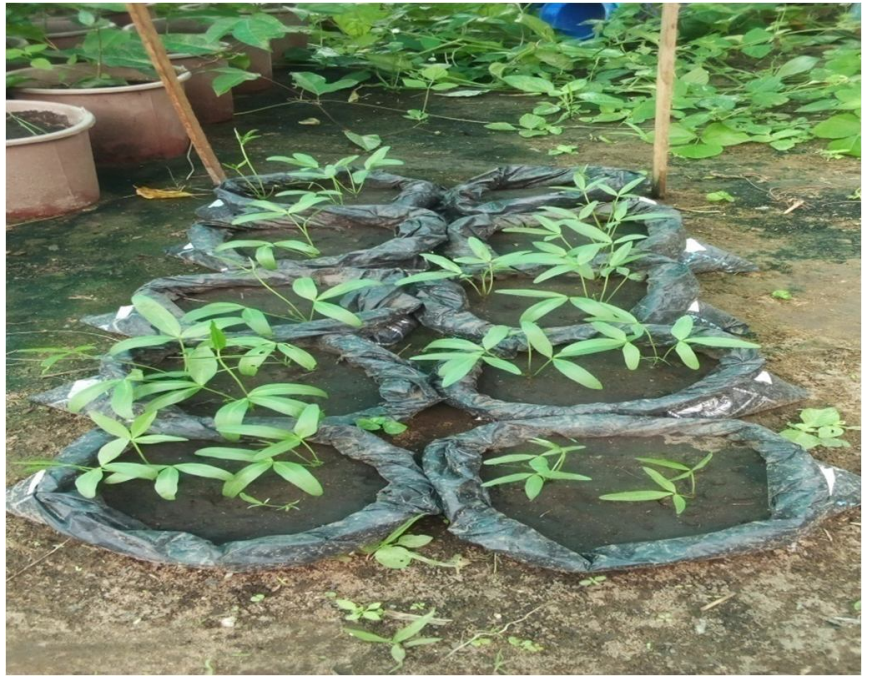

Plate 3. Bambara groundnut seedlings before inoculation.

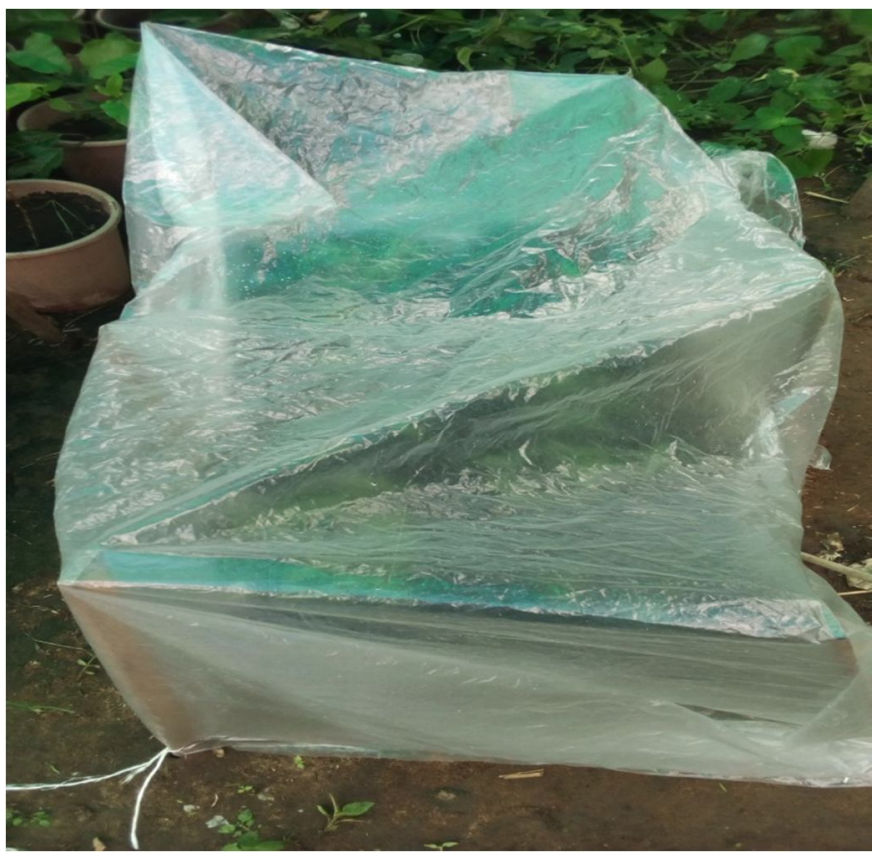

Plate 4. Bambara groundnut seedlings after inoculation in humid chamber.

Effect of plant extracts, synthetic fungicide, concentration and extraction methods on percentage inhibition of the radial growth of Aspergillus niger in culture

Table 1 shows that there was a significant effect $(P=$ 0.05 ) of plant extracts and synthetic fungicide on percentage growth inhibition of $A$. niger in culture. The synthetic fungicide (Mancozeb) had the highest percentage growth inhibition (75.00) than the plant extracts which was significantly higher than Turmeric

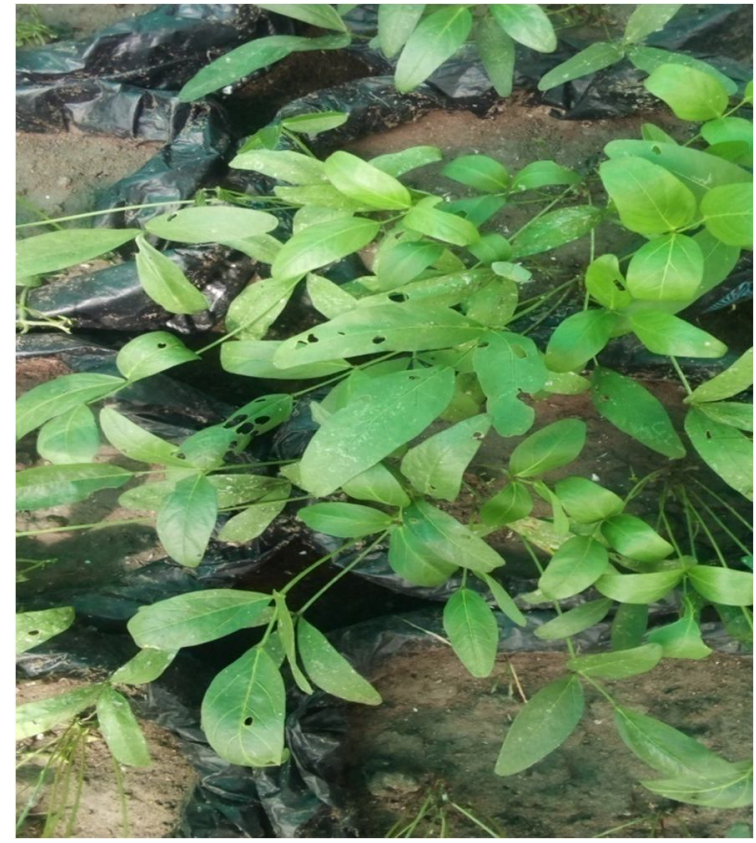

Plate 5. Bambara groundnut seedlings showing symptoms of infection.

(Curcuma longa) (72.56) and Garlic (Allium sativum) (70.07). This was followed by Turmeric (72.56) which was also significantly $(P=0.05)$ higher than Garlic (70.07) which was also the least.

Table 1 also shows that there was significant difference in the effects $(P=0.05)$ of the various concentration levels. The result shows that the higher the concentration, the higher the value of inhibition percentage. This trend occurred in all the days of the culture. The concentration of $30 \mathrm{~g} / \mathrm{ml}$ had the highest inhibition value (100\%) for day $1,93.23 \%$ for day 2 and $85.50 \%$ for day 3 . This was followed by concentration level of $20 \mathrm{~g} / \mathrm{ml}$ which also produced higher inhibition than $10 \mathrm{~g} / \mathrm{ml}$ in all the days of the culture. Concentration of $10 \mathrm{~g} / \mathrm{ml}$ had the least inhibition values in the days in culture but all concentrations did better than the control.

Table 1 also showed that there was significant difference $(P=0.05)$ in the effect of extraction method on the inhibition of Aspergillus $\mathrm{spp}$ in culture. Cold maceration with methanol gave a significantly higher $(P=$ 0.05) growth inhibition value than Soxhlet extraction with ethyl acetate method in day 1 , while in day 2 and 3 respectively. Soxhlet extraction method gave a significantly $(P=0.05)$ higher difference.

Interaction effect of plant extracts, synthetic fungicide and concentration levels on percentage inhibition of the radial growth of Aspergillus niger in culture

Table 2 shows that there was a significant effect $(0.05)$ 
Table 1. Effect of plant extracts, synthetic fungicide, concentrations and extraction methods on percentage inhibition of radial growth of Aspergillus niger in culture.

\begin{tabular}{lccc}
\hline \multirow{2}{*}{ Treatments } & \multicolumn{3}{c}{ Incubation period (days) and growth inhibition (\%) } \\
\cline { 2 - 4 } & $\mathbf{1}$ & $\mathbf{2}$ & $\mathbf{3}$ \\
\hline Plant extract (PE) & & & \\
Turmeric (TU) & 72.56 & 60.82 & 50.94 \\
Garlic (GA) & 70.07 & 50.36 & 39.67 \\
Mancozeb & 75.00 & 75.00 & 75.00 \\
LSD $_{0.05}$ & 3.66 & 2.79 & 1.96 \\
Concentration (Conc) & & & \\
10 & & & \\
20 & 93.43 & 71.29 & 60.25 \\
30 & 96.74 & 83.71 & 75.07 \\
0 & 100.00 & 93.23 & 85.50 \\
LSD $_{0.05}$ & 0.00 & 0.00 & 0.00 \\
& 3.94 & 1.98 & 1.31 \\
Extraction method (EM) $_{\text {CMM }}$ & & & \\
SOE $_{\text {LSD }}$ & 73.05 & 60.43 & 54.22 \\
\hline Key: CMM Cold & 71.94 & 63.68 & 56.18 \\
& 6.37 & 5.44 & 2.89 \\
\hline
\end{tabular}

Key: $\mathrm{CMM}=$ Cold Maceration with Methanol, SOE = Soxhlet extraction with ethyl acetate, Conc $=$ Concentration, $\mathrm{PE}=$ Plant extract, $\mathrm{EM}=$ Extraction Method.

Table 2. Interaction effect of plant extracts, synthetic fungicide and concentration levels on percentage inhibition of the radial growth of Aspergillus niger in culture.

\begin{tabular}{|c|c|c|c|c|c|c|c|c|c|c|c|c|}
\hline \multirow{2}{*}{ Treatment } & \multicolumn{12}{|c|}{ Incubation period (days) and growth inhibition (\%) } \\
\hline & \multicolumn{4}{|c|}{1} & \multicolumn{4}{|c|}{2} & \multicolumn{4}{|c|}{3} \\
\hline PE/Conc & 10 & 20 & 30 & 0 & 10 & 20 & 30 & 0 & 10 & 20 & 30 & 0 \\
\hline GA & 89.17 & 91.11 & 100.00 & 0.00 & 43.88 & 69.81 & 87.74 & 0.00 & 28.13 & 56.96 & 73.59 & 0.00 \\
\hline TU & 91.11 & 99.11 & 100.00 & 0.00 & 69.99 & 81.32 & 91.96 & 0.00 & 52.62 & 68.25 & 82.90 & 0.00 \\
\hline Mancozeb & 100.00 & 100.00 & 100.00 & 0.00 & 100.00 & 100.00 & 100.00 & 0.00 & 100.00 & 100.00 & 100.00 & 0.00 \\
\hline $\mathrm{LSD}_{0.05}$ & & 6.69 & & & & 3.86 & & & & 2.63 & & \\
\hline
\end{tabular}

Key: Conc $=$ concentration, $\mathrm{PE}=$ plant extract, $\mathrm{GA}=$ garlic, $\mathrm{TU}=$ turmeric .

between interaction of plant extracts and concentration levels on the percentage growth inhibition of $A$. niger in culture. The synthetic fungicide (Mancozeb) had significantly higher $(P=0.05)$ percentage growth inhibition $(100.00)$ at the different concentration levels than the plant extracts.

Turmeric $\times 30 \mathrm{~g} / \mathrm{ml}$ also consistently produced higher inhibition value $(100.00)$ followed by turmeric $\times 20 \mathrm{~g} / \mathrm{ml}$ which had a higher percentage growth inhibition (99.11\%) than turmeric $\times 10 \mathrm{~g} / \mathrm{ml}$ which had the least percentage growth inhibition (91.11\%) in day 1 . This trend also occurred in all the days of the culture with inhibition values $91.96 \%, 82.90 \%$ at day 3 , for turmeric $\times 30 \mathrm{~g} / \mathrm{ml}$.

For garlic $\times 30 \mathrm{~g} / \mathrm{ml}$ concentration continuously gave significantly $(P=0.05)$ higher growth inhibition values than the other concentration levels with inhibition values of
$100.00,87.74$ and 73.59 in day 1 to 3 respectively. This was followed by garlic $\times 20 \mathrm{~g} / \mathrm{ml}$ concentration at day 1 . This trend also continued in day 2 and 3 with inhibition values $87.74 \%$ at day $2,73.59 \%$ at day 3 , while garlic $\times 10 \mathrm{~g} / \mathrm{ml}$ concentration level $(89.17 \%)$, had the least percentage growth inhibition. The result also showed that all the plant extracts at the different concentration levels did better than control.

\section{Interaction effect of plant extract and extraction method on percentage inhibition of the radial growth of Aspergillus niger in culture}

Table 3 shows that interaction between plant extracts and extraction methods also had a significant $(P=0.05)$ effect 
Table 3. Interaction effect of plant extract and extraction method on percentage inhibition of the radial growth of Aspergillus niger in culture.

\begin{tabular}{|c|c|c|c|c|c|c|}
\hline \multirow{2}{*}{ Treatment } & \multicolumn{6}{|c|}{ Incubation period (days) and growth inhibition (\%) } \\
\hline & \multicolumn{2}{|c|}{1} & \multicolumn{2}{|c|}{2} & \multicolumn{2}{|c|}{3} \\
\hline PE/EM & CMM & SOE & CMM & SOE & CMM & SOE \\
\hline GA & 72.22 & 67.92 & 49.07 & 51.64 & 38.80 & 40.54 \\
\hline TU & 72.20 & 72.92 & 57.23 & 64.41 & 48.87 & 53.02 \\
\hline $\mathrm{LSD}_{0.05}$ & 5.42 & & 4.43 & & 2.68 & \\
\hline
\end{tabular}

Key: $\mathrm{CMM}=$ cold maceration with methanol, $\mathrm{SOE}=$ soxhlet extraction with ethyl acetate, $\mathrm{GA}=$ garlic, $\mathrm{TU}=$ turmeric.

on percentage growth inhibition on $A$. niger in culture. Garlic $\times$ cold maceration with methanol $(\mathrm{GA} \times \mathrm{CMM})$ had a higher percentage growth inhibition $(72.22 \%)$ than turmeric $\times$ cold maceration with methanol $(\mathrm{TU} \times \mathrm{CMM})$ in day 1 , while in day 2 and 3 respectively, $(\mathrm{TU} \times \mathrm{CMM})$ had a higher percentage growth inhibition ((57.23), (48.87)).

Turmeric $\times$ Soxhlet extraction with ethyl acetate (TU×SOE) had a higher percentage growth inhibition $(72.92 \%)$ than garlic $\times$ Soxhlet extraction with ethyl acetate $(\mathrm{GA} \times \mathrm{SOE})$ in day 1 . This trend was consistent for all the days of the culture.

\section{Interaction effect of concentration and extraction method on percentage inhibition of the radial growth of Aspergillus niger in culture}

Table 4 shows interaction between concentration and extraction methods had significant $(P=0.05)$ effect on the percentage growth inhibition of $A$. niger in culture. There was a significant difference in interaction between concentration and extraction methods in day 1 of the culture. Soxhlet extraction with ethyl acetate $\times 30 \mathrm{~g} / \mathrm{ml}$ concentration gave a significantly $(P=0.05)$ higher growth inhibition value than cold maceration extraction with methanol, with the inhibition value $(95.43 \%)$ in day 2 , while in day 3 , cold maceration with methanol extraction method gave a significantly $(P=0.05)$ higher growth inhibition value than in Soxhlet extraction, with inhibition value of $86.59 \%$.

Soxhlet extraction with ethyl acetate (SOE) $\times 20 \mathrm{~g} / \mathrm{ml}$ concentration consistently gave significantly $(0.05)$ higher percentage growth inhibition values than in cold maceration with methanol; with the inhibition values in all days in culture $(97.78 \%),(85.45 \%),(77.49 \%)$ in day 1 to 3 respectively. This was followed by cold maceration with methanol $\times 10 \mathrm{~g} / \mathrm{ml}$ concentration which produced higher growth inhibition value than Soxhlet extraction with ethyl acetate $\times 10 \mathrm{~g} / \mathrm{ml}$ concentration in day $1(96.85 \%)$, while at day 2 and 3 respectively, Soxhlet extraction with ethyl acetate $\times 10 \mathrm{~g} / \mathrm{ml}$ produced higher growth inhibition values than cold maceration methods with the inhibition values $(73.85 \%),(62.84 \%)$. All the extraction methods at the different concentration levels also produced significantly $(P=0.05)$ higher percentage growth inhibition values than the control $(0 \mathrm{~g} / \mathrm{ml})$ which showed no growth inhibition. It was also observed that the effect of concentration by extraction methods was deteriorating with time in the culture with day 3 having the lowest percentage growth inhibition values.

Interaction effect of plants extracts, concentration and extraction method on percentage inhibition of the radial growth of Aspergillus niger in culture

Table 5 shows that there was significantly $(P=0.05)$ interaction effect of the two plant extracts used, concentration and extraction methods on percentage growth inhibition of $A$. niger in culture. The synthetic fungicide (mancozeb) had significantly higher $(P=0.05)$ percentage growth inhibition (100.00) at the different concentration levels than the plant extracts in the days in culture.

Garlic $(\mathrm{GA}) \times$ cold maceration with methanol $(\mathrm{CMM}) \times 10$ and $30 \mathrm{~g} / \mathrm{ml}$ respectively gave highest growth inhibition value together with $30 \mathrm{~g} / \mathrm{ml}$ garlic $(\mathrm{GA}) \times$ Soxhlet extraction with ethyl acetate (100.00), this was followed by $\mathrm{GA} \times \mathrm{SOE} \times 20 \mathrm{~g} / \mathrm{ml}(93.33 \%)$ in day 1 and $\mathrm{GA} \times \mathrm{SOE}$ $\times 30 \mathrm{~g} / \mathrm{ml}(92.78 \%)$ in day 2 but in day $3, \mathrm{GA} \times \mathrm{CMM} \times 30$ $\mathrm{g} / \mathrm{ml}$ gave significantly $\mathrm{P}=0.05$ higher growth inhibition value $(76.89 \%)$ than the other concentration by extraction methods.

Turmeric (TU) $\times$ Soxhlet extraction with ethyl acetate $(\mathrm{SOE}) \times 20$ and $30 \mathrm{~g} / \mathrm{ml}$ respectively gave highest growth inhibition value together with $30 \mathrm{~g} / \mathrm{ml}$ turmeric $(T U) \times$ cold maceration with methanol $(100.00)$, this was followed by $\mathrm{TU} \times \mathrm{CMM} \times 20 \mathrm{~g} / \mathrm{ml}(98.22 \%)$ in day 1 and $\mathrm{TU} \times \mathrm{SOE}$ $\times 30 \mathrm{~g} / \mathrm{ml}(93.51 \%)$ in day 2 but in day $3, \mathrm{TU} \times$ SOE $\times 30$ $\mathrm{g} / \mathrm{ml}$ gave significantly $\mathrm{P}=0.05$ higher growth inhibition value $(82.92 \%)$ than the remaining concentration of the extraction method. All the extraction methods at the different concentration levels with the different plant extracts also produced significantly $(P=0.05)$ higher percentage growth inhibition values than the control $(0$ $\mathrm{g} / \mathrm{ml}$ ) which showed no growth inhibition.

It was also observed that the effects of plant extracts by concentration by extraction methods was reducing with 
Table 4. Interaction effect of concentration and extraction method on percentage inhibition of the radial growth of Aspergillus niger in culture.

\begin{tabular}{|c|c|c|c|c|c|c|}
\hline \multirow{2}{*}{ Treatments } & \multicolumn{6}{|c|}{ Incubation period (days) and growth inhibition (\%) } \\
\hline & \multicolumn{2}{|c|}{1} & \multicolumn{2}{|c|}{2} & \multicolumn{2}{|c|}{3} \\
\hline Conc/EM & CMM & SOE & CMM & SOE & CMM & SOE \\
\hline 10 & 96.85 & 90.00 & 68.72 & 73.85 & 57.66 & 62.84 \\
\hline 20 & 95.70 & 97.78 & 81.97 & 85.45 & 72.64 & 77.49 \\
\hline 30 & 100.00 & 100.00 & 91.04 & 95.43 & 86.59 & 84.40 \\
\hline 0 & 0.00 & 0.00 & 0.00 & 0.00 & 0.00 & 0.00 \\
\hline $\mathrm{LSD}_{0.05}$ & \multicolumn{2}{|c|}{5.87} & \multicolumn{2}{|c|}{4.13} & \multicolumn{2}{|c|}{2.30} \\
\hline
\end{tabular}

Key: $\mathrm{CMM}=$ cold maceration with methanol, $\mathrm{SOE}=$ soxhlet extraction with ethyl acetate, Conc = concentration, EM = extraction method.

Table 5. Interaction effect of plant extracts, concentration and extraction method on percentage inhibition of the radial growth of Aspergillus niger in culture.

\begin{tabular}{|c|c|c|c|c|c|c|c|}
\hline \multirow{3}{*}{$\begin{array}{l}\text { Treatments } \\
\mathrm{PE} / \text { Conc/ EM }\end{array}$} & & \multicolumn{6}{|c|}{ Incubation period (days) and growth inhibition (\%) } \\
\hline & & \multicolumn{2}{|c|}{1} & \multicolumn{2}{|c|}{2} & \multicolumn{2}{|c|}{3} \\
\hline & & $\mathrm{CMM}$ & SOE & $\mathrm{CMM}$ & SOE & CMM & SOE \\
\hline \multirow{4}{*}{ GA } & 10 & 100.00 & 78.33 & 43.86 & 43.89 & 27.02 & 29.25 \\
\hline & 20 & 88.89 & 93.33 & 69.74 & 69.89 & 51.29 & 62.62 \\
\hline & 30 & 100.00 & 100.00 & 82.70 & 92.78 & 76.89 & 70.29 \\
\hline & 0.0 & 0.00 & 0.00 & 0.00 & 0.00 & 0.00 & 0.00 \\
\hline \multirow{4}{*}{ TU } & 10 & 90.56 & 91.67 & 62.31 & 77.67 & 45.95 & 59.28 \\
\hline & 20 & 98.22 & 100.00 & 76.18 & 86.46 & 66.64 & 69.86 \\
\hline & 30 & 100.00 & 100.00 & 90.41 & 93.51 & 82.87 & 82.92 \\
\hline & 0.0 & 0.00 & 0.00 & 0.00 & 0.00 & 0.00 & 0.00 \\
\hline Mancozeb & & 100.00 & 100.00 & 100.00 & 100.00 & 100.00 & 100.00 \\
\hline $\mathrm{LSD}_{0.05}$ & & \multicolumn{2}{|c|}{9.57} & \multicolumn{2}{|c|}{5.74} & \multicolumn{2}{|c|}{3.69} \\
\hline
\end{tabular}

Key: $\mathrm{CMM}=$ cold maceration with methanol, $\mathrm{SOE}=$ soxhlet extraction with ethyl acetate, $\mathrm{PE}=$ plant extracts, EM = extraction method, Conc = concentration, TU = turmeric, GA = garlic .

time in the culture with day 3 having the lowest percentage growth inhibition value in all the days in the culture.

\section{DISCUSSION}

\section{Seed health / germination test}

The result of germination / seed health test showed that the two varieties of Vigna subterranean had different germination rates. The reasons for disparity in germination rates of Bambara groundnut varieties from localities may have different explanations. These could be as a result of differences in crop management practices, varying prevalence of pest and diseases in the areas, socio-economic differences with its attendant effect on ability to afford the purchase of varying inputs that aid in high quality output (Dornbos, 1995). Management practices also affect the quality of seeds: poor management practices leads to unhealthy and less vigorous seeds while good management practices will leads to healthy and more vigorous seeds (Dornbos, 1995).

Results of the current study obtained from the standard germination test showed that the cream white (Var A) had the least germination potential. This suggested that seed viability was lower in cream white landrace compared to the black speckled (Var B) landrace. Previous studies (Sinefu, 2011; Mabhaudhi et al., 2013; Zondi, 2013) that focused on plain Bambara groundnut reported that dark coloured seeds performed better compared to light coloured seeds. In this case, black speckled landrace performed better than the cream white landrace, suggesting that speckles could be a useful selection criterion for seed quality in Bambara groundnut 
improvement.

\section{Isolation of seed borne fungal organism}

The fungal organism isolated from the seeds of black speckled landrace was Aspergillus niger (Plate 2) which was in line with the works of Pitt and Samson (2000) and Ellis (2006). It was also observed that Aspergillus niger (Plate 4) was associated with damage to plumule of germinating seedlings (Abiola and Oyetayo, 2016).

\section{Effect of plant extract, synthetic fungicide, concentration and extraction method and their interactions on percentage inhibition on the radial growth of Aspergillus niger in culture}

The effects of plant extract, their concentration and synthetic fungicide (Mancozeb) on percentage inhibition of the radial growth of Aspergillus niger isolated from two varieties of Bambara groundnut seeds showed that there was a significant difference $(P=0.05)$ in effects of various plant extracts and synthetic fungicide (Mancozeb).

The synthetic fungicide consistently had significantly $(P=0.05)$ higher percentage inhibition values than the extracts of turmeric and garlic. This is in agreement with the findings of Saranya et al. (2018) and Tijjani et al. (2014) that Mancozeb is used to protect many fruit, vegetable and field crops against a wide spectrum of fungi diseases.

The result of this research showed that the antifungal activity of the plant extracts increases as the concentration increases from 10 to $30 \mathrm{~g}$ and thus the higher the percentage inhibition in all the days in culture. Turmeric with concentration level of $30 \mathrm{~g} / \mathrm{ml}$ inhibited the organism better than the other concentration levels as shown in the results. This is in line with the works of Amadioha and Obi (1999) and Udo et al. (2001), who reported that the efficacy and safety of some plant extracts against early blight of tomato, increases with concentration increasing toxicity of the active biocompounds.

The study also showed that the higher the concentration, the higher the percentage inhibition values in all the days in culture. The concentration level of 30 $\mathrm{g} / \mathrm{ml}$ inhibited the organism better than the other concentration levels; this is in line with the work of Ohazurike et al. (2003) who reported that most fungi showed a gradual decline in growth with increase in concentration in the medium.

\section{CONCLUSION AND RECOMMENDATIONS}

From the findings of this work, it could be inferred that the fungal organism isolated was responsible for the cause of seed rot of Vigna subterranean (L). Therefore, it is consequently been implicated to be the major cause of seed deterioration, leading to poor viability and loss in seedling vigour. Also the variety, source of plant and age of plant could affect the rate of germination. All plant extract and Mancozeb inhibited the fungi in-vitro. Mancozeb had the highest percentage inhibition. Curcuma longa performed better than Allium sativum.

The study also showed that the higher the concentration, the higher the percentage inhibition values in all the days in culture. The concentration level of 30 $\mathrm{g} / \mathrm{ml}$ inhibited the organism better than the other concentration levels. Cold maceration with methanol (CMM) had the highest percentage inhibition. Based on the present results, the tumeric and garlic extracts could be suggested as an alternative to Mancozeb.

Farmers should endeavor to purchase their seed from reputable or certified seed outlets. Farmers should conduct viability or germination test to ensure adequate plant establishment estimate in the field. Curcuma longa was as good as synthetic fungicide (Mancozeb), therefore, more studies should be conducted on this plant extract to study the bio-compounds that have biocidal effect so as to be able to commercialize their production and to make them more available to farmers to reduce the rate of application of synthetic fungicides which is detrimental to human health, the environment and also not easily biodegradable.

\section{REFERENCES}

Abiola C, Oyetayo VO, 2016. Isolation and biochemical characterization of microorganisms associated with the fermentation of Kersting's groundnut (Macrotyloma geocarpum). Res J Microbiol, 11: 47-55.

Akhtar JV, Kumarjha V, Kumar A, Lai HC, 2009. Occurrence of banded leaf and sheath blight of maize in Jhark hand with reference to diversity in Rhizoctonia solani. Asian J Agric Sci, 1(2): 32-35.

Amadioha AC, Obi VI, 1999. Control of anthracnose disease of cowpea by Cymbopgon citratus and Ocimum gratissimum. Acta Phytopathologica Entomologici, 34: 85-89.

Amuti K, Larbi M, 1981. Post-harvest losses in Bambara groundnut and geocarpa groundnut seeds stored under traditional conditions in Ghana. Tropical Grain Legumes Bulletin, 23:20-23.

Azam-Ali SN, Sesay A, Karikari SK, Massawe FJ, Aguilar-Manjarrez J, Bannayam, Hampson KJ, 2001. Assessing the potential of underutilized crop- a case study using Bambara groundnut. J Exper Agric, 37:433-472.

Azwanida NN, 2015. A review on the extraction methods use in medicinal plants, principles, strength and limitations. Med Aromatic Plants, 4:196.

Baudoin JP, Mergeai G, 2001. Grain Legumes in Crop Production in Tropical Africa. P313-317.

Chowdhury H, Banerjee T, Walia S, 2008. In-vitro screening of Curcuma longa $\mathrm{L}$. and its derivatives as antifungal agents against Helminthosporum oryzae and Fusarium solani. Pest Res J, 20(1): 69.

De Tempe J, 1963. On methods of seed health testing- principles and practice. Proc Int Seed Test Assoc, 28: 153-165.

Dornbos Jr DL, 1995. Production Environment and Seed Quality. Basic Mechanisms and Agricultural Implications, A.S. Basra, Ed., pp 119145, Food Products Press, London, UK.

Ellis BW, Bradley FM, 1992. The Organic Gardener's Handbook of Natural Insect and Disease control. Rodale Press. ISBN 0-87596- 
753-1.

Ellis D, 2006. Mycology on line. The University of Adelaide, Australia.

FAO, 1985. Prevention of postharvest food losses. Training Series No. 10, Rome. Food and Agricultural Organizations of the United Nations. 122pp.

Golob P, Stong FR, Asante EO, 1996. A review of the storage and marketing system of major food grains in Northern Ghana. Report of the Natural Resources Institute, Chahtan Maritime, Kent ME4 4TB, UK.

Mabhaudhi T, Modi AT, Beletse YG, 2013. Growth, phenological and yield responses of Bambara groundnut (Vigna subterranean (L).Verdc) landrace to impose water stress under field conditions. South Afr J Plant Soil, 30: 69-79.

Markson A, Omosun A, Gumana E, Matsunaga BF, Amadioha AC, Udo SE, 2014. Differential responses of Solanum tuberosum (L) and Impomea batata (L) to three rot pathogens. Int Res, 2(1): 40-51

Mkandawire $\mathrm{CH}, 2007$. Review of Bambara groundnut (Vigna subterranean (L).Verdc) production in the sub-Sahara Africa. Agric J, 2: $464-470$.

NRC, 2006. Lost Crops of Africa, Volume II: Vegetables, National Research Council, Development, Society, and Cooperative Policy and Global Affairs, Washington. NewYork, Academic Press, pp 354.

Ohazurike NC, Omuh MO, Emeribe EO, 2003. The use of seed extracts of the physic nut (Jatropha curcas L.) in the control of maize weevil (Sitophilus zeamaise M.) in stored maize grains (Zea mays L.). Global J Agric Sci, 2(2): 86-88.

Pitt JI, Sampson RA, 2000. Integration of Modern Taxonomic Methods for Penicillium and Aspergillus Classification. Harwood Academic Publishers, Amsterdam. pp 83-113.

Sangoyomi TE, 2004. Post-Harvest Fungal Deterioration of Yam (Dioscorea rotundata Poir) and its control. Thesis. International Institute of Tropical Agriculture. Ibadan, Nigeria, p. 179.

Saranya R, Anadani VB, Akbari LF, Vanthana M, 2018. Effect of botanicals and bioagents on growth of Aspergillus niger (Van Tiegh) causing black mold in onion. Int J Pure App Biosci, 6(4): 431-436.

Sinefu F, 2011. Bambara groundnut response to controlled environment and planting date associated water stress. M.Sc Dissertation, University of KwaZulu-Natal, South Africa.

Sulton BC, 1980. The coelomycetes fungi Imperfecti with Pycinidia acervuli and stromata. Common wealth mycological institute Kew, surrey, England. 696pp.

Tijjani A, Adebitan SA, Gurama AU, Haruna SG, Safiya T, 2014. Effect of some selected plant extracts on Aspergillus flavus, a causal agent of fruit rot disease of tomato (Solanum lycopersicum) in Bauchi State. Int J Biosci, 4(12): 244-252.

Tweneboah CK, 2000. Modern Agriculture in the Tropics, Food Crops, Co-wood Publishers.

Udo SE, Madunagu BE, Isemin CD, 2001. Inhibition of growth and sporulation of fungal pathogens on sweet potato and yam by garlic extract. Nig J Bot, 14: 35-39.

Ungphaiboon $S$, Supavita $T$, Singchangchai $P$, Sungkarak $S$, Rattanasuwan $\mathrm{P}$, Itharat $\mathrm{A}, 2005$. Study on antioxidant and antimicrobial activities of Turmeric liquid clear soap for wound treatment of HIV patients. Songklanakarin J Sci Technol, 27(2): 269578.
Upendra RS, Khadewal P, Reddy AHM, 2011. Turmeric Powder (Curcuma longa Linn.) as an antifungal agent in plant tissue culture studies. Int J Eng Sci, 3(11): 7599-7904.

Warui $M, 1984$. Bruchid infestation of cowpea varieties in the field. Insect Sci Appl, 5: 238-286.

Whipps JM, 1987. Effects of media on growth and interactions between a range of soil borne glass pathogens and antagonistic fungi. New Pathol, 107:127-142.

Yao D, Bonny BS, Zorobi IA, 2005. Observations Perliminaries de voandzou (Vigna subterranean (L).Verdc) de Cote d'Ivoire, Agronomie. Soc Environ Sci, 9: 249-258.

Zondi LZ, 2013. Responses of Bambara groundnut (Vigna subterranean (L). Verdc) landrace to field and controlled environment conditions of water stress. M.Sc.Dissertations, University of KwaZuluNatal, South Africa.

Citation: Iwuagwu CC, Kpadobi RC, Nwogbaga AC, Salaudeen MT, Iheaturu DE, Onejeme FC, 2019. Fungitoxic effects of some plant extracts on seedborne fungi pathogens of Bambara groundnut in Awka South of Anambra State, Nigeria. Adv Med Plant Res, 7(2): 4453. 